\title{
EXPERIMENTAL STUDY OF LIPOSOMAL DOCETAXEL ANALYSIS OF DOCETAXEL INCORPORATION AND STABILITY
}

\author{
Y.M. Krasnopolsky ${ }^{1}$, A.S. Dudnichenko ${ }^{2, *}$ \\ ${ }^{1}$ Department of Biotechnology, Biophysics and Analytical Chemistry of the National Technical University, \\ "Kharkiv Polytechnick Institute”, Kharkiv 61002, Ukraine \\ ${ }^{2}$ Department of Oncology and Pediatric Oncology of Kharkiv Medical Academy of Postgraduate Education, \\ Kharkiv 61176, Ukraine
}

\begin{abstract}
Aim: The article presents the results of developing the composition and technology of obtaining the liposomal form of docetaxel. The effect of the phospholipid composition of the membrane, ionic strength, $\mathrm{pH}$, temperature, cryoprotectant type, and other factors on the stability of liposomes and the docetaxel incorporation has been considered. Results: Reduction of toxicity of the liposomal form of docetaxel $\left(\mathrm{LD}_{50}-137 \pm 7.7 \mathrm{mg} / \mathrm{kg}\right)$ was found in comparison with its free form $\left(L D_{50}-101 \pm 6.3 \mathrm{mg} / \mathrm{kg}\right)$. Preservation of nanosize particle after lyophilization has been shown. Conclusions: As a result of the studies, the optimal composition and technological scheme for obtaining liposomes containing docetaxel have been developed allowing large-scale production of docetaxel in liposomal form.
\end{abstract}

Key Words: liposomes, docetaxel, liposomal drugs, toxicity.

The taxanes, in particular docetaxel (Doc), are widely used as chemotherapy agents for treatment of breast, ovarian, prostate, stomach, non-small cell lung cancers, squamous cell carcinoma of the head and neck. Doc $\left(\mathrm{C}_{43} \mathrm{H}_{53} \mathrm{NO}_{14}\right)$ is a semisynthetic drug produced by chemical modification of the substance extracted from the needles of the European yew. A wide spectrum of antitumor activity is determined by the unique mechanism of Doc action. The drug facilitates accumulation of tubulin in intracellular structures - microtubules and prevents their breakdown, which leads to abnormality of mitosis and interphase processes in tumor cells [1]. Moreover, Doc exhibits activity against some cells, producing an excess of P-glycoprotein [2], which is encoded by the gene of multidrug resistance. Doc is effective for treatment of metastatic cancer as the second line of chemotherapy for most solid tumors [3]. At present, Doc is intensively studied in combined chemotherapy with other antitumor drugs including monoclonal antibodies [4, 5]. At the same time, Doc is known to cause cardiac toxicity, dermatological toxicity, chronic fatigue syndrome, mucositis, allergic reactions, peripheral neuropathy. Also patients treated with Doc often experience febrile neutropenia, which requires urgent hospitalization [6].

One of the most important trends in modern pharmaceutical technologies consists in designing targeted therapeutic systems. Nanosomal carriers of drugs aimed at increasing the target effects as well as bioavailability of cytotoxic drugs are successfully used [7-14]. In recent years, there have been reports of Doc incorporation into nanoparticles of various polymer carriers, pegylated particles and liposomes (Lip) of natural and synthesized lipids [10, 13-20].

Submitted: October 02, 2016.

*Correspondence: E-mail: dudas_kharkov@ukr.net Abbreviations used: Doc - docetaxel; DPHG - dyphosphatidylglycerol; HPLC - high performance liquid chromatography; Lip liposomes; PC - phosphatidylcholines; $\mathrm{Ph}$ - phospholipids.
Bearing in mind that the bioavailability and stability of pharmaceutical preparations depends to a great extent on the solubility of the active agent, the aim of our study is to create a soluble form of Doc incorporated in Lip. The report summarizes our data on the properties of Lip-Doc obtained at a different ratio of lipid components forming nanoparticles. We have analyzed stability of such preparations, Doc incorporation and their toxicity.

\section{MATERIALS AND METHODS}

Lipid substances. We used natural phospholipids $(\mathrm{Ph})$ : phosphatidylcholines (PC) from egg yolks (Biolek, Kharkiv, Ukraine) or LIPOID E PC S (Lipoid GmbH, Germany) of $96 \%$ purity (impurities: phosphatidyl ethanolamine not more than (NMT) 1.0\%, Lyso PC NMT $1.0 \%$, sphingomyelin NMT 1.0\%); dyphosphatidylglycerol (DPHG) from bovine cardiac muscle (Biolec) of $92 \%$ purity (impurities: phosphatidyl ethanolamine NMT 1.5\%, PC NMT 6.0\%, sphingomyelin and phosphatidylserine NMT 1\%). The oxidation degree of fatty acids was determined from the oxidation index value measured as a ratio of optical densities at $215 \mathrm{~nm}$ and $233 \mathrm{~nm}$ in ethanol. Oxidation index of lipids used was: PC - NMT 0.3; DPHG - NMT 1.0.

Preparation of Lip. Lip were prepared according to the technology that we developed earlier [21]. To distribute evenly the components of the lipid film, Doc was dissolved in an organic solvent containing $\mathrm{Ph}$ in a certain ratio and concentration. The solvent was completely removed on a rotary vacuum evaporator at a temperature of $38-42^{\circ} \mathrm{C}$ and then the solvent residues were evaporated in a stream of nitrogen. The resulting thin lipid film was hydrogenated in an aqueous lactose solution in a heated bath at a temperature of $40-42^{\circ} \mathrm{C}$ to obtain a homogeneous suspension. The resulting suspension was either ultrasonicated for 20-25 min depending on the temperature of the transition phase of the lipids, or extruded through a two-layer polycarbonate $0.2 \mu \mathrm{m}$ filter to obtain Lip of uniform size. Homogenization was also carried out by extrusion on a homogenizer 
Microfluids-110 at a preset pressure [21]. The emulsion was sterilized by filtration $(0.8-0.22 \mu \mathrm{m})$, poured into vials and freeze-dried followed by filling with an inert gas. As cryoprotectants, we used lactose (or trehalose) at various ratios $\mathrm{Ph}$ :cryoprotectant $(1: 1,1: 2,1: 3,1: 4)$. The process of Lip sublimation consists of two stages. First, we remove free water up to $80-85 \%$, at a constant rate of drying (this stage takes $40-50 \%$ of overall time). At the second stage, we remove up to $95-98 \%$ of bound water (those integrated in Lip structure). The resulting sterile lyophilized Lip-Doc samples were dissolved in a sterile aqueous solvent. The composition obtained appeared like a homogenous white emulsion.

Analytical methods. Lip size was measured by photon correlation spectroscopy on nanosizer Shimadzu SALD-1701 using a semiconductor laser at a wavelength of $375 \mathrm{~nm}$ and a temperature of $30^{\circ} \mathrm{C}$. The content of Doc and impurities in the samples of composition was assayed by high performance liquid chromatography (HPLC). The Agilent 1100 chromatograph was used with a chromatographic column $150 \times 4.6 \mathrm{~mm}$ filled with Zorbax SB-CIS sorbent with a particle size of $3.5 \mu \mathrm{m}$ («Hewlett Packard»); a mobile phase was methanol:acetonitrile:water (16:13:21); the flow rate was $1 \mathrm{ml} / \mathrm{min}$; detection at a wavelength of $232 \mu \mathrm{m}$; the detection time $180 \mathrm{~min}$; the column temperature was $28^{\circ} \mathrm{C}$. Thin layer chromatography was carried out on Silufol plates in chloroform:methanol:water (65:25:4). To identify Ph, we used standard Ph samples from «Sigma». The oxidation index was determined by UV-spectroscopy at two wavelengths: $233 \mathrm{~nm}$ and $215 \mathrm{~nm}$.

Toxicity in vivo. We used Balb/c mice weighing 18-22 g. The drugs were administered intravenously twice daily. The signs of toxicity and death of animals were recorded within the first hour after the administration of the study drugs, then at 3,8 and 12 hours, and then for the next 10 days with the administration of the study drug. All mice living on the $10^{\text {th }}$ day of the experiment were euthanized by dislocation of the cervix under anesthesia. To determine the $\mathrm{LD}_{50}$, Kerber method was used [22]. To achieve greater accuracy, six doses of the compositions under study $(60-160 \mathrm{mg} / \mathrm{kg}$ ) were administered spaced by the same interval of $20 \mathrm{mg} / \mathrm{kg}$. Six series of experiments were conducted, with three groups of animals 10 mice each. LD $_{100}$ value for each composition was determined with Taxotere ("Sanofi Aventis") being a reference drug. $L_{50}$ was then calculated using the formula:

$$
L D_{50}=L D_{100}-\Sigma(Z \cdot D) / m,
$$

where $Z$ is the average number of dead animals in two successive doses; $D$ is the difference between two successive doses (dose interval); $m$ is the number of animals in one group. The statistical analysis was carried out using MS Excel.

\section{RESULTS AND DISCUSSION}

Stability of Lip and substance integration into Lip composition is influenced by ionic strength, $\mathrm{pH}$ value, temperature of technological process, time of every cycle, pressure, ultrasound intensity, etc. It is important to use specified concentration of buffer mixtures, i.e. minimal salt concentration for buffer, allowing to maintain specified $\mathrm{pH}$ value. In our experiments, $\mathrm{pH}$ was shifted to the acidic range (by adding buffer mixture) for Doc stabilization. Phase behavior of $\mathrm{pH}$ bilayer is determined by van der Waals interactions between neighboring molecules of lipids in bilayer, which in turn depends on lipids packaging in bilayer and chain length of fatty acid. Ph with longer "tails" have bigger area of interaction, which leads to the increase of interaction force and thus to lipid immobilization.

The choice of cryoprotectant, its concentration and form as well as the time-point of its use in processing procedure are essential factors for preparing Lip-incorporated compositions. Early supplementation with carbohydrate cryoprotectant (for instance, lactose or trehalose) may be disadvantageous considering Lip size and decreased incorporation of active substance. Also we have demonstrated that the more was amount of sugar used for nanoparticles protection during lyophilization, the less was the increase in Lip size after rehydration.

The data on the efficacy of Doc incorporation into Lip at different ratios of components - membrane-building lipids, Doc and cryoprotectant (prior to and after lyophilization) is presented in Table 1. At a 1:15 Doc to $\mathrm{Ph}$ ratio, Doc incorporation into Lip amounts to $80-87 \%$. The increased amount of lipids (1:18-1:20) results in almost complete Doc incorporation into Lip. Meanwhile, Lip size in emulsion samples practically does not depend on Doc to $\mathrm{Ph}$ ratio. More than $85 \%$ of nanoparticles were within the range of $100-160 \mathrm{~nm}$. We also noticed quite high rate of Doc inclusion in lipid bilayer. It is also necessary to take into account the possibility direct interaction between Ph and Doc, which may result in formation of the complex.

Table 1. Characteristics of Lip-Doc samples before and after lyophilization

\begin{tabular}{|c|c|c|c|c|c|c|c|}
\hline $\begin{array}{c}\text { Doc, } \\
\text { mg }\end{array}$ & $\begin{array}{c}\text { Ph, mg } \\
\text { PC:DPHG }\end{array}$ & $\begin{array}{c}\text { Lac- } \\
\text { tose, } \\
\mathrm{mg}\end{array}$ & $\begin{array}{c}\text { Doc: } \\
\text { Ph } \\
\text { ratio }\end{array}$ & $\begin{array}{l}\text { Doc in- } \\
\text { cor- } \\
\text { pora- } \\
\text { tion into } \\
\text { Lip, \% }\end{array}$ & $\begin{array}{l}\text { Lip size, } \\
\text { nm, be- } \\
\text { fore lyo- } \\
\text { philization }\end{array}$ & $\begin{array}{c}\text { Doc } \\
\text { incorpora- } \\
\text { tion into Lip, } \\
\% \text {, after lyo- } \\
\text { philization }\end{array}$ & $\begin{array}{l}\text { Lip size, } \\
\text { nm, after } \\
\text { lyophiliza } \\
\text { tion }\end{array}$ \\
\hline \multirow[t]{2}{*}{20} & 300 & & & & & & \\
\hline & $\begin{array}{c}\text { PC:DPHG } \\
270: 30\end{array}$ & 300 & $1: 15$ & $80-87$ & $95-160$ & $80-85$ & $300-500$ \\
\hline \multirow[t]{2}{*}{20} & 350 & & & & & & \\
\hline & $\begin{array}{c}\text { PC:DPHG } \\
320: 30\end{array}$ & 1050 & $1: 18$ & $>97$ & $100-160$ & $95-97$ & $120-160$ \\
\hline \multirow[t]{2}{*}{20} & 400 & & & & & & \\
\hline & $\begin{array}{c}\text { PC:DPHG } \\
370: 30\end{array}$ & 1600 & $1: 20$ & $>98$ & $100-150$ & $95-98$ & $100-160$ \\
\hline
\end{tabular}

Addition of negatively charged $\mathrm{Ph}$, namely DPHG into Lip composition may be advantageous for Lip stabilization in processing procedure as well as upon rehydration of the lyophilized product with an aqueous solvent. As seen from Table 1, Lip size in lyophilized samples depends on the $\mathrm{Doc}$ to $\mathrm{Ph}$ ratio and on lipid substance concentration. At 1:15 Doc to Ph ratio, two groups of nanoparticles are formed 120-180 nm (about $80 \%$ ) and $300-500 \mathrm{~nm}$ (about $20 \%$ ). It is fair to assume that low lipid content of Lip results in the release of a certain fraction of Doc from nanoparticles at lyophilization with accompanying formation of Lip with considerably larger size. Moreover, increase of Ph and cryoprotectant, 
in particular, PC and lactose in Lip sample composition, standardizes and stabilizes lipid particles after their rehydration. We have demonstrated that after lyophilization Lip size of dried samples remained unchanged.

Using HPLC, we studied Doc stability after Lip lyophilization. We confirmed the identity of quantitative and qualitative composition after drying and consequent rehydration of Lip samples. Impurity content and its retention time do not change, which may reflect Doc stability in the process of Lip preparation and their subsequent freezedrying; the content of impurities in lyophilized sampled did not exceed $0.5 \%$. The results of stability study of Lip Doc (2-year storage below $0^{\circ} \mathrm{C}$ ) are given in Table 2 .

Table 2. Stability of Doc in liposomal form during storage

\begin{tabular}{lccccc}
\hline $\begin{array}{c}\text { Characteristics } \\
\text { of the drug }\end{array}$ & $\begin{array}{c}\text { Particle } \\
\text { size, nm }\end{array}$ & $\begin{array}{c}\text { Doc incor- } \\
\text { poration } \\
\text { into Lip, \% }\end{array}$ & $\begin{array}{c}\text { Time of emul- } \\
\text { sion reconsti- } \\
\text { tution, min }\end{array}$ & pH & $\begin{array}{c}\text { Impuri- } \\
\text { ties, \% } \\
\text { (HPLC) }\end{array}$ \\
\hline $\begin{array}{l}\text { The drug after } \\
\text { preparation }\end{array}$ & $100-160$ & $>95.0$ & NMT 3 & 5.45 & 2.3 \\
$\begin{array}{l}\text { The drug after } \\
2 \text { years of storage }\end{array}$ & $110-180$ & $>90.0$ & NMT 3 & 5.38 & 2.8 \\
\hline
\end{tabular}

Note: * DPHG-Lip at a ratio of Doc:Ph - 1:20.

Therefore, the stability of the liposomal form of Doc was confirmed with Doc incorporation at the level of not less than $90 \%$ and Lip size of $110-180 \mathrm{~nm}$.

The toxicity of Lip samples containing Doc was compared with that of conventional dosage form of Doc upon intravenous injection of the compositions under study. We evaluated $L_{50}$ of Lip form of Doc: containing DPHG (DPHG-Lip) at a 1:20 ratio of Doc:Ph (see Table 1) and a Lip form containing only PC (PC-Lip). ReduCtion of toxicity of the liposomal form of Doc $\left(\mathrm{LD}_{50} 137 \pm\right.$ $7.7 \mathrm{mg} / \mathrm{kg}$ for DPGH-containing Lip) was found in comparison with its free form $\left(L_{50} 101 \pm 6.3 \mathrm{mg} / \mathrm{kg}\right)(p<0.1)$. We observed identical results using liquid and lyophilized forms, which proved stability of pharmacological properties of studied compositions after lyophilization. Besides, it was demonstrated that PC increase in composition resulted in the increase of number of survived mice while using Lip containing negatively charged lipid DPHG.

To sum up, a composition and a technological platform for creating a liposomal form of Doc have been proposed and a lyophilized preparation containing Doc, natural phosphatidylcholine and diphosphatidyl glycerol has been obtained. As a cryoprotectant, disaccharide lactose was used. The particle size in nanosizes with the incorporation of Doc into the Lip being at least $90 \%$. The dependence of $L D_{50}$ on the composition of the drug was studied. The stability of the drug was demonstrated within 2 years.

\section{REFERENCES}

1. Ringel I, Horwitz SB. Studies with RP 56976 (Taxotere): a semisynthetic analogue of Taxol. J Natl Cancer Inst 1991; 83: 288-91.

2. Afanasieva DA, Baryshnikova MA, Baryshnikov AYu. Molecular mechanisms of overcoming multiple drug resistance by liposomal anticancer drugs. Rus Biother J 2015; 14: 3-11 (in Russian).

3. Zyrianov SK, Belousov YuB. Generics in oncology: Comparative analysis of Docetaxel generics. Pharmateka 2008; (18): 56-9 (in Russian).
4. Burris HA. Docetaxel (Taxotere) plus trastuzumab (Herceptin) in breast cancer. Semin Oncol 2001; 28: 38-44.

5. Stadnichenko AV, Krasnopolskyi YuM, Shvets VI. Some aspects of manufacturing liposomal form of Oxaliplatin. Fine Chem Techn 2015; 10: 60-5 (in Russian).

6. Ho MY, Mackey JR. Presentation and management of docetaxel-related adverse effects in patients with breast cancer. Cancer Manag Res 2014; 6: 253-9.

7. Hryhorieva AS, Katsai AG, Konakhovytch NF, et al. Nanomedicine in Ukraine: 25 years of application of lipoisomal medicinal products. Pharmacom 2016; (1): 3644 (in Russian).

8. Krasnopolskyi YuM, Stepanov AE, Shvets VI. Lipid technological platform for developing new dosage forms and transport of pharmaceutical substances. Biopharm J 2011; 3: 10-8 (in Russian).

9. Pivniuk VM, Timovskaia YuO, Ponomareva OV, et al. Use of liposomal forms of chemotherapeutics in patients with resistant breast cancer. Oncology 2007; 9: 120-4 (in Russian).

10. Stadnichenko AV, Krasnopolskyi YuM, Shvets VI. Technology for producing liposomal forms of Irinotecan (review). Biopharm J 2014; 6: 3-9 (in Russian).

11. Fitch RM, Wojdyla JK, Blackledge JA, et al. Antitumor activity of liposomal docetaxel prodrug MNK010 on PC 3 human prostate xenograftsin mice. J Cancer Res 2015; 76: 1930-40.

12. Kajiura S, Hosokawa A, Yoshita H, et al. Phase I study of Docetaxel plus Nedaplatin in patients with metastatic or recurrent esophageal squamous cell carcinoma after Cisplatin plus 5-Fluorouracil treatment. Am J Clin Oncol 2016; 39: $13-7$.

13. Rangar S, Sirohi P, Agarwal V. Nanoparticle-based drug delivery system. Braz Arch Biol Technol 2014; 57: 209-22.

14. Fan Y, Zhang Q. Development of liposomal formulation: From concept to clinical investigations. Asian J Pharm Sci 2013; 8: 81-7.

15. Afrous Y, Farnaz E, Sima R, et al. Preparation and in vitro evaluation of pegylated Nano-liposomal Formulation containing Docetaxel. Scientia Pharmaceutica 2007; 77: 453-64.

16. Deeken JF, Slack R, Weiss GI, et al. A Phase I study of liposomal encapsulated docetaxel (LE-DT) in patients with advanced solid tumor malignancies. Cancer Chemother Pharmacol 2013; 71: 827-33.

17. Koch MC, Krieger ML, Stolting D, et al. Overcoming chemotherapy resistance of ovarian cancer cells by liposomal cisplatin: Molecular mechanisms unveiled by gene expression profiling. Biochem Pharmacol 2013; 85: 1077-90.

18. Krasnopolsky YM, Balabanyan VY, Shobolov DL, Shvets VI. Prospective clinical applications of nanosized drugs. Rus J Gen Chem 2013; 8: 2524-40.

19. Mahalingam D, Nemunaitis JJ, Malik L, et al. Phase I study of intravenously administered ATI-1123, liposomal docetaxel formulation in patients with advanced solid tumors. Cancer Chemother Pharmacol 2014; 74: 1241-50.

20. Zhang H, Li RY, Lu Z, et al. Docetaxel-loaded liposomes: preparation, $\mathrm{pH}$ sensitivity, pharmacokinetics, and tissue distribution. J Biomed Biotechnol 2012; 13: 981-9.

21. Krasnopolskyi YuM, Dudnichenko AS, Shvets VI. Pharmaceutical biotechnology: Bionanotechnology in pharmacy and medicine. Kharkiv: NTU "KhPI", 2011. 227 p. (in Russian).

22. Preclinical study of medicinal products. Methodical guides. Stefanov AV, ed. K: Avitsenna, 2002: 384-94 (in Russian). 